\title{
Observation and Epidemiology of Ocular Trauma in Children: Hospital based Study
}

\author{
Vinitkumar S Kamble', Gyan Bhaskar ${ }^{2}$, Bibhuti P Sinha ${ }^{3}$, Anita ambastha ${ }^{4}$, Aayushi ${ }^{5}$, Rajnee Sinha ${ }^{6}$ \\ ${ }^{1}$ Fellow Anterior Segment, SCEH, Lahan Nepal, ${ }^{2}$ Additional Professor, ${ }^{3}$ Professor, ${ }^{4}$ Associate Professor, ${ }^{5}$ Senior \\ Resident, ${ }^{6}$ Junior Resident, Regional Institute of Ophthalmology, IGIMS, Patna
}

\begin{abstract}
Background: This study was designed to identify the causes, demographic, clinical profile \& classify the patients according to the ocular trauma classification group.

Method: 60 children of age fifteen year or less, with ocular injury, who had presented to emergency services/out-patient department of the Regional Institute of Ophthalmology (RIO), IGIMS medical college $\&$ hospital, Patna (Bihar) were included. Demographic data, nature and cause of injury, duration between injury \& presentation to the hospital and diagnosis were recorded. Evaluation of visual acuity, anterior segment and fundus was done.

Results: Majority of injuries occurred in children $7 \mathrm{yrs}$ and older (64.7\%). There were $50(83.33 \%)$ boys and $10(16.66 \%)$ girls. $40(66.67 \%)$ of cases presented within $24 \mathrm{hrs}$ of the injury while $20(33.33 \%)$ of cases presented after more than $24 \mathrm{hr}$ after trauma. Rural patients comprised 39 out of 60 (65\%) while urban were 21 out of $60(35 \%)$. Most of the patients $n=36(60 \%)$ belonged to average socioeconomic status fallowed by low socioeconomic status $n=20(33.33 \%) \&$ high socioeconomic status $n=4(6.67 \%)$. Most of the children $\mathrm{n}=35(58.33 \%)$ were in their primary school. The highest proportion of injuries occurred outside (eg streets, roads, playgrounds, schools) $n=40(66.67 \%)$ followed by home $n=20$ (33.33\%). Conclusions: Eye trauma in children occur most frequently outdoors. Early diagnosis, management and prevention of complications of ocular injuries can be possible by educating parents and children.
\end{abstract}

Keywords: Ocular trauma, Paediatric, Conflict, Open globe, Closed globe.

\section{Introduction}

Eye injuries are a major \& under-recognized cause of disability \& ocular morbidity that especially affects the young. The public health importance of such ocular trauma is undeniable. Injuries generate a significant $\&$ often unnecessary toll in terms of medical care, human suffering, long term disability, productivity loss, rehabilitation services and socioeconomic cost.

Studies indicate that one out of every five adults have a history of ocular trauma. In paediatric group,

\section{Corresponding author:}

\section{Dr. Gyan Bhaskar}

Additional Professor, Regional Institute of Ophthalmology, IGIMS, Sheikhpura, Patna-800014, Bihar Mobile No- 09431048077,

Email-drgyan6@gmail.com these rates are $12 \%$ to $38 \%$, making ocular trauma the most avoidable cause of childhood blindness. Penetrating ocular trauma is a well-known cause of visual impairment in young adults and children leading to blindness. Cost burden due to ocular trauma is also an important issue. Severe ocular trauma may require expensive hospitalization, specialist treatment, prolonged follow-up \& visual rehabilitation. The indirect, secondary economic impact of ocular trauma, due to loss of work or school days, is harder to estimate.

Approximately 1.6 million people are blind owing to ocular trauma, 2.3 million are bilaterally visually impaired \& 19 million have unilateral visual loss. ${ }^{[1]}$ Besides loss of vision, earnings (job opportunities) \& productivity, it increases the cost to society because of increased health care spending. ${ }^{[2]}$ 
Children are particularly subject to ocular trauma because of their predilection towards hazardous play, outdoor activities \& relative lack of judgement. Regardless of the cause of trauma, overall management of the children eye does not differ significantly from that of adult except when amblyopia is involved, which is a possibility with any child who is injured before 6 or 7 years of age. Identifying the aetiologies of such injuries among children may help in determining most effective measures to prevent the visual loss.

Serious eye injuries in children are common and visual outcome can be devastating. ${ }^{[3-6]}$ One-third of all vision loss in the first decade of life is due to trauma. ${ }^{[7]}$ However nearly $90 \%$ of eye injuries can be prevented by relatively simple measures. ${ }^{[8,9]}$ The purpose of this study was to analyse the demographic profile, nature / type of injury, circumstances, cause of injury, time gap between injury and presentation to the hospital of the paediatric ocular trauma during one year of study period. Patients were then classified according to the latest ocular trauma classification Birmingham Eye Trauma Terminology System (BETT) ${ }^{[10]}$ and Open-Globe Injury Classification ${ }^{[10,11]}$ and Ocular Trauma Score (OTS) ${ }^{[12,13]}$

\section{Materials \& Method}

Study site: Emergency or out-patient department of Regional Institute of Ophthalmology (RIO), IGIMS Medical College \& Hospital Patna, Bihar.

Study duration: 12 months (from August 2014 to July 2015)

Study design: This was an observational study. 60 cases of age $\leq 15$ years and either of gender of penetrating ocular trauma were consecutively selected for this study fulfilling the inclusion and exclusion criteria.

Inclusion criteria: All the ocular trauma patients of age $\leq 15$ years of either gender. Exclusion criteria:

Patients/ Parents refusing to sign the informed consent or not admitted will be excluded.

Patient not coming for regular follow-up.

Rupture of the globe with vitreous or uveal tissue prolapsed.

Following data were collected from each patient

Demographic data
Address (rural/urban): Patients residing in a place with no district hospital were categorized as rural.

Literacy status: determined on the basis of educational status as reported by patients themselves or their parents.

\section{Occupation of parents}

Financial status: It was based on monthly income

Cause of injury

Complete history of the nature and circumstances of the injury

Time gap between injury and presentation to the hospital

Detailed ophthalmic work up was carried out to assess the severity of injury and structural damage

Statistical Analysis: Patient related data were collected and statistical analysis was done by using Microsoft Excel Software.

\section{Results}

TABLE 1: Age Incidence

\begin{tabular}{|l|l|l|}
\hline Age in years & No. of Cases & Percentage \\
\hline$<$ than 7 yrs & 21 & $35.00 \%$ \\
\hline 7 to $<12$ yrs & 19 & $31.67 \%$ \\
\hline 12 to 15 yrs & 20 & $33.33 \%$ \\
\hline
\end{tabular}

Table 2 shows 50 males (boys) (83.33\%) and 10 females (girls) $(16.66 \%)$ with male to female ratio of $5: 1$.

TABLE 2: Gender Incidence

\begin{tabular}{|l|l|l|}
\hline Sex & No. of Cases & Percentage \\
\hline Male & 50 & $83.33 \%$ \\
\hline Female & 10 & $16.66 \%$ \\
\hline
\end{tabular}

Geographic distribution of the patients showed that $65 \%$ of patients were from rural area (that is 39 out of 60 cases) and 35\% patients were from urban areas (that is 21 out of 60 cases $)$. Only $6.67 \%(n=4)$ were from high income/ high socioeconomic status (Table 3). 
TABLE 3: Income Status of Studied Subjects

\begin{tabular}{|l|l|l|}
\hline Income Status & No. of Patients & Percentage \\
\hline Low & 20 & $33.33 \%$ \\
\hline Average & 36 & $60.00 \%$ \\
\hline High & 04 & $6.67 \%$ \\
\hline
\end{tabular}

Table 4 shows that most of the injuries involved in primary literacy status (33 patients out of 60 ) in $55 \%$ followed by under school age $09(15.00 \%)$.

TABLE 4: Literacy Status of the Studied Subjects

\begin{tabular}{|l|l|l|}
\hline Literacy Status & No. of Patients & Percentage \\
\hline Under school age (<3 years of age) & 09 & $15.00 \%$ \\
\hline Primary (class Nursery to 5th) & 33 & $55.00 \%$ \\
\hline Middle (6th to 8th) & 08 & $13.33 \%$ \\
\hline High (9th and 10th) & 06 & $10.00 \%$ \\
\hline Illiterate & 04 & $6.68 \%$ \\
\hline
\end{tabular}

Table 5 showed that majority of patients, 40 out of $60(66.67 \%)$ had injury when they were outdoors (street). In street, we have taken roads, playgrounds and schools. $33.33 \%$ patients had injury at home

\section{TABLE 5: Place of Injury}

\begin{tabular}{|l|l|l|}
\hline Place of injury & No. of Patients & Percentage \\
\hline Street (Roads, playgrounds, school) & 40 & $66.67 \%$ \\
\hline Home (House and Lawn) & 20 & $33.33 \%$ \\
\hline
\end{tabular}

The elapsed time between injury and presentation was most commonly, same day in (66.67\%) patients followed by 2-7 days in 17 patients $(28.33 \%)$. It was noted that in low income status group, the delay period was much longer than in high income status group (Table 6).

\section{TABLE 6: Time of Presentation}

\begin{tabular}{|l|l|l|}
\hline Time & No. of Patients & Percentage \\
\hline Same day & 40 & $66.67 \%$ \\
\hline Between 2-7 days & 17 & $28.33 \%$ \\
\hline $8-30$ days & 02 & $3.33 \%$ \\
\hline$>30$ days & 01 & $1.66 \%$ \\
\hline
\end{tabular}




\section{Discussion}

More than one third of eye injuries occur in paediatric age group and may cause lifelong disability due to their immature motor skill and their tendency to imitate adult behaviour without evaluating risks (Thordarson U, Ragnasson AT et al). ${ }^{[14]}$

Serious ocular trauma gives rise to structural damage or functional loss which imposes an enduring burden throughout the most productive years of life (Robert JC). ${ }^{[15]}$

In the present study boys outnumbered girls in the frequency of eye trauma by a ratio of 5:1. Our results were consistent Strahlman E et al. ${ }^{[16]}$, Cascairo MA et al ${ }^{[17]}$, Khatry SK et al ${ }^{[18]} \&$ Vasnaik A et al ${ }^{[19]}$. In general boys are granted more liberty than girls and tend to spend more time outside with their friends with less adult supervision (Ariturk N, Sahin $\mathrm{M}$ et al). ${ }^{[20]}$

In this study almost $65 \%(n=39)$ injuries occurred in children greater than 7 years of age. This was consistent with the studies done by Gorden $\mathrm{Y}$ J et al in Lesotho ${ }^{\text {[21] }}$ and Niramen $\mathrm{M}$ et al in Finland ${ }^{[22]}$.

The majority of the patients belonged to the average income status $(\mathrm{n}=36,60 \%)$ followed by low $(\mathrm{n}=20$, $33.33 \%)$ and high-income status $(\mathrm{n}=04,6.67 \%)$. Only a small number of patients belonged to high income status in our study. This shows that there is greater level of awareness \& education among the high-income group. Therefore, socioeconomic status and family negligence are important factors in eye injuries in children. Our results were consistent with the study done by Ariturk $\mathrm{N}$ et al ${ }^{[20]}$.

In this study, most of the children were in primary school $(n=33,55.00 \%)$ because they are more often exposed to the outdoor environment and more physically active and take more risks to gain acceptance by their peers. Conflict has been recognized as a frequent cause of eye injury in the young by Rapaport et al ${ }^{[23]}$.

In this study most ocular injuries $(n=40,66.67 \%)$ occurred when children were outside their home (on street, road, school, playground etc). This is consistent with the studies done by Dalia M Sebaity et al ${ }^{[24]}$ and Kaimbo et al ${ }^{[25]}$.

In this study playing (either playing in school, street, outdoor etc) to be the most prevalent mode of injury accounting for almost $40-50$ percent of cases. In all the three age groups playing was found to be equally important and most common mode of injury. These observations were consistent with Niramen et al ${ }^{[22]}$, Rapaport et al ${ }^{[23]}$, Moreira et al ${ }^{[26]}$.

\section{Conclusions}

Eye trauma in children occurs most frequently in outdoors but different outdoor sports are also important for the health. Early diagnosis, management and prevention of complications of ocular injuries can be possible by educating parents and children.

\section{Source of Funding: Self \\ Conflict of Interest: None}

Ethical Clearance: Taken

\section{References}

1. Epidemiology of childhood ocular trauma in a North eastern Colombian Region. Juan C. Serrano et al: MD; Patricia Chalela, MPH; Juan D. Arias, MD. Arch Ophthalmol 2003; 121: 1439-1445.

2. Abeba Bejiga et al: Causes \& visual outcomes of perforating ocular injuries among Ethiopian patients. Community Eye Health 2001; 14(39): 45-46.

3. Werner $\mathrm{S}$ et al: Article on injuries of the eyes in children. Acta Ophthalmol 1952; 30: 97-104.

4. Sternberg P Jr, DeJuan E Jr, Michals RG et al: An Article review on: Penetrating ocular injuries in young patients: mode of injuries \& visual results. Retina 1984; 4: 5-8.

5. Scharf J, Zonis S et al: A Perforating injuries of the eye in childhood. Pediatric Journal of Ophthalmol 1976; 13: 326- 328.

6. Alfaro DV, Chaudhary NA, Walonker AF et al. Article on Penetrating eye injuries in young children. Retina 1994; 14: 201-205.

7. (USA) National Society of Frequent Blindness \& Vision Problem in the United States. New York: article of: National Society to Prevent Blindness 1980: 32-33.

8. MacEven CJ et al: An Aricle regarding ocular injuries. J R Coll Surg Edinb 1999; 44: 317-323.

9. May DR, Kunn FP, Morris RW et al. The epidemiology of serious eye injuries from the United States of America eye injury registry. Grafts Arch Chin Exp Ophthalmol 2000; 238: 153-157. 
10. 10. Definitions \& Classification in ocular trauma, Chapter 4. James T Banta, textbook, Page no. 41 (BETT Classification) Table: 4.1

11. Pieramici DJ et al. Perspective - A system for classifying mechanical injuries of the eye (Globe). Am J. Ophthalmol 1997; 123: 820-831.

12. Dante J. Pieramici, MD; Paul Sternberg, Jr, MD; Antonio Capone, JR, MD et al (The Ocular Trauma Classificatiion Group). A system of classifying mechanical injuries of the eye (GLOBE). Am J Ophthalmol 1997 June; 123: 820-831.

13. Kuhn $\mathrm{F}$ et al; the OTS - Ocular Trauma Score Ophthalmol Clin: North Am. 2002: 15 (163-165) [PubMed] with permission of Elsevier.

14. Thordarson U, Ragnasson AT, Gudbrandson B et al: an observational study on ocular trauma in 105 patients. Acta Opthal (Copenh) 1979 Oct; 57(5): 922-928.

15. Robert JC et al : Article :The burden of serious ocular injury. British Journal Opthalmol 1996; 80: 585.

16. Stralman L, Elman M, Daub L, Baker S. et al: Cause of pediatric eye injuries: a population based study. Arch Ophthalmol 1990; 108: 603-606.

17. Cascairo MA, Mazow ML, Prager TC et al. Pediatric ocular trauma: a retrospective survey. J Pediatr Ophthalmol Strabismus 1994; 31: 312-317.

18. Khatry SK, Lewis AE, sehein OD et al. Analytical: hospital based study on epidemiology of ocular trauma in rural Nepal. Br Journal Ophthalmol 2004 Apr; 88(4): 456-460.
19. Vasnaik A, Vasu U, Battu RR, Kurian M, George $S$ et al: Mechanical eye (globe) injuries in children. J Pediatric Ophthalmol Strabismus 2002 Jan-Feb; 39(1): 5-10.

20. Ariturk N, Sahin M, Oge I, Erkan D, Sullu Y et al: Evaluation of ocular trauma in children between a 0-12 age group published in Turk $\mathrm{J}$ Pediatrics on 1999 Jan-Mar; 41(1): 43-52

21. Gorden YJ, Moketee $M$ et al: pediatric ocular injuries in leso-tho. Doc Ophthalmol 1982; 53: 283 289.

22. SG Jaison, SE Silas, SK Chopra et al: An article review on childhood admission with perforating ocular injuries in a hospital in northwest India. IJO 1994; 421(4): 199- 201.

23. Rapaport I, Romem M, Kinek M et al. Eye injuries in children in Israel; a nationwide collaborative study. Arch Opthalmol 1990; 108: 376-9.

24. Dalia M El-Sabaity, Wael Soliman, Asmaa MA, Soliman, Ahmed M Fathalla et al: Pediatric eye injuries in upper Egypt. Clinical Ophthalmology 2011; 5: 1417- 1423.

25. Kaimbo WK, Spileers W, Missotten L et al: study on Ocular emergencies in kinhasa (Democratic Republic of Congo) Bull Soc Belge Ophthalmol 2002; 284: 49-53.

26. Moreira CA JR, Debert Ribeiro, M. Belfort R et al: Epidemiological study of eye injuries in Brazilian children. Journal Arch Ophthalmol 1988; 106: 781784 . 